\section{Variation of rs3754689 at lactase gene and inhibitors in admixed Brazilian patients with hemophilia A}

Hemophilia A is an X-linked bleeding disorder due to mutations in the factor VIII gene (F8). The most clinically relevant complication of hemophilia $\mathrm{A}$ is the development of neutralizing alloantibodies (inhibitors) against factor VIII, ${ }^{1}$ occurring in up to $30 \%$ of severe patients. Inhibitors impair hemostasis during FVIII replacement, leading to hemorrhages that are difficult to control, disability and a lower quality of life. The use of bypassing agents is required in most cases to treat or prevent bleeding, representing a more expensive and less effective alternative hemostatic therapy than exogenous FVIII.

Brazil has the fourth largest world population of hemophilia A, with approximately 10,000 individuals $^{3}$ and a prevalence of 1:10,000 live males. Treatment of hemophilia represents a burden of 350 million dollars per year with the purchase of coagulation factor concentrates, of which approximately $25 \%$ is spent annually for the treatment of immune tolerance induction and bleeding events for around 600 patients with clinically-relevant inhibitors. ${ }^{4}$ Therefore, a predictive genetic marker of inhibitor development is urgently needed. Several studies have attempted to identify a predictive genetic marker of inhibitor development to be used in the clinical practice. ${ }^{5}$ The most comprehensive study to date uncovered a set of genomic variants associated with inhibitor risk in a small cohort of Italian patients with hemophilia A using whole exome sequencing (WES) data. ${ }^{6}$ They showed that the T allele of an SNP (rs3754689) in the lactase ( $L C T)$ gene, located in a conserved haplotype region, was associated with protection against FVIII alloantibodies [Odds Ratio (OR) 0.56; 95\% Confidence Interval (CI): 0.33-0.94]. LCT encodes lactase-phlorizin hydrolase, responsible for the digestion of lactose with declining activity after weaning for most humans and all other mammals. Cis-acting allelic variants in an enhancer region upstream of $L C T$ cause the persistence of lactase into adulthood in many different human populations, and these variants have been subjected to recent positive selection.?

We speculated whether this polymorphism would be suitable as a protective genetic marker of inhibitor development in an admixed Brazilian cohort of patients with hemophilia A. We enrolled individuals with severe [FVIII activity (FVIII:C) <1\%] and moderately-severe (FVIII:C $1-2 \%$ ) hemophilia A, who were genotyped for rs3754689 using Taqman (Id C_2104738_10; Thermo Fisher, Waltham, MA, USA). Patients were participants from three different studies: the HEMFIL Study $(\mathrm{n}=61)^{8,9}$ and the BrazIT Study $(n=55),{ }^{10}$ and a local study that enrolled patients attending the Hemophilia Treatment Center in Minas Gerais state $(n=44)$. All patients/guardians signed an informed consent form and the studies were approved by local ethical committees.

Inhibitor status was defined as positive $\left(\mathrm{Inh}^{+}\right)$when inhibitor level was $\geq 0.6$ Bethesda units (BU) per $\mathrm{mL}$ detected on two separate occasions within a 2-4 week period. High titer inhibitors were considered as $>5 \mathrm{BU}$ $\mathrm{mL}^{-1}$ at least once in a lifetime, and low titer when inhibitors titers were always $\leq 5 \mathrm{BU} \mathrm{mL} \mathrm{m}^{-1}{ }^{11}$ Patients defined as negative for inhibitor ( $\left(\mathrm{Inh}^{-}\right)$were treated for at least 50 exposure days (ED) and did not develop inhibitors. Associations were evaluated using Pearson's $\chi^{2}$ test with simulated $P$-value implemented in $\mathrm{R}$ 3.4.4.

A total of 160 patients were included, of whom 149
Table 1. Characteristics of the patients included in the study.

\begin{tabular}{lccc} 
Characteristic & All patients & Inhihitor No inhilbitor \\
Severity of hemophilia A, n (\%) & & & \\
Severe & 149 & $83(56)$ & $66(44)$ \\
Moderately-severe & 11 & $3(27)$ & $8(73)$ \\
rs3754689 genotype, $\mathrm{n}$ & & & \\
T/T & 16 & 8 & 8 \\
T/C & 75 & 40 & 35 \\
C/C & 69 & 38 & 31 \\
\hline
\end{tabular}

Inhibitor titer, $\mathrm{n}(\%)$

$\begin{array}{lccc}\text { High titer } & - & 73(85) & - \\ \text { Low titer } & - & 13(15) & - \\ \text { F8 genotype, n (\%) } & & & \\ \text { Inv1+ } & 7 & 5(71) & 2(29) \\ \text { Inv22-1+ } & 41 & 31(76) & 10(24) \\ \text { Inv22-2+ } & 19 & 15(79) & 4(21) \\ \text { Inv1/22 negative* } & 67 & 34(51) & 33(49) \\ \text { Not available } & 26 & 1(4) & 25(96)\end{array}$

n: number. *Individuals who tested negative for inversions of introns 1 and 22 of factor VIII gene.

had severe and 11 had moderately-severe hemophilia A. Eighty-six patients $(53.7 \%)$ were Inh $^{+}$, of whom 73 $(84.9 \%)$ were high titer. Allelic frequency analysis showed no difference in rs3754689 between $\mathrm{Inh}^{+}$and Inh ${ }^{-}$groups $(P=0.931)$ nor between high and low titers $(P=0.386)$ (Table 1$)$. No statistically significant deviations from expected Hardy-Weinberg Equilibrium were observed $(P=0.999)$. As expected, there was an association between the presence of $F 8$ intronic inversions (introns 1 and 22) and inhibitor status $(P=0.022)$.

The same result was observed when rs3754689 genotypes of $\mathrm{Inh}^{+}$patients were compared with a large cohort $(n=5,822)$ of healthy individuals from the EPIGEN Brazil Initiative $(P=0.792)$. The EPIGEN represents a widerange genomic landscape of Latin America, with around 2.2 million SNP of three population-based Brazilian cohorts comprising diverse demographic studies. ${ }^{12}$ In a global populational overview, the diversity data from the 1,000 Genome Project ${ }^{13}$ show an increased frequency of the protective T-allele in some groups, such as Europeans, Asians and mixed race Americans (Table 2).

In the light of the lack of association between rs3754689 and inhibitor development in our study, we investigated whether variants surrounding this particular variant in Brazilians showed association. To understand the genetic architecture of the LCT region, a linkage disequilibrium analysis using PLINK was performed across $200 \mathrm{Mb}$ flanking the rs3754689 variant in 5,822 individuals from the EPIGEN cohort. Alleles at 321 SNP associated to form 19 different haplotypes in the Brazilian population. A previous investigation of the polymorphisms related to lactase persistence in 981 healthy Brazilians revealed 26 haplotypes, with the most common persistent allele highly associated with European ancestry in the populations analyzed. ${ }^{14}$ This is not an unexpected finding considering the high genetic variability of the Brazilian population.

Indeed, admixed populations such as Brazilians represent a prolific environment for genetic association studies due to the country's particular demographic history. Over the last 500 years, the genetic compounds of Europeans and Africans have been absorbed into the 
Table 2. Allelic frequencies of SNP rs3754689 in Brazilian and Italian patients with hemophilia A, cohort EPIGEN Brazil and 1,000 Genome data from the five major human population groups.

\begin{tabular}{|c|c|c|c|c|c|}
\hline \multirow{2}{*}{ Groups } & \multicolumn{2}{|c|}{ Frequency } & \multirow[t]{2}{*}{ Population } & \multicolumn{2}{|c|}{ Frequency } \\
\hline & C & $\mathbf{T}$ & & C & $\mathbf{T}$ \\
\hline Brazilian HA patients & 0.67 & 0.33 & $\operatorname{Inh}+(\mathrm{n}=86)$ & 0.67 & 0.33 \\
\hline$(n=160)$ & & & Inh- $(\mathrm{n}=74)$ & 0.66 & 0.34 \\
\hline EPIGEN Brazil $^{18}$ & 0.68 & 0.32 & Salvador $(\mathrm{n}=1,246)$ & 0.61 & 0.39 \\
\hline \multirow[t]{2}{*}{$(\mathrm{n}=5,822)$} & & & Bambuí (n= 925) & 0.72 & 0.28 \\
\hline & & & $\begin{array}{l}\text { Pelotas }(\mathrm{n}=3,651) \\
\text { Bambuí + Pelotas }(\mathrm{n}=4,576)\end{array}$ & $\begin{array}{l}0.70 \\
0.70\end{array}$ & $\begin{array}{l}0.30 \\
0.30\end{array}$ \\
\hline Italian HA patients ${ }^{12}$ & - & - & $\operatorname{Inh}^{+}$exome $(\mathrm{n}=17)$ & 0.68 & 0.32 \\
\hline \multirow[t]{3}{*}{$(\mathrm{n}=253)$} & & & Inh$^{-}$exome $(\mathrm{n}=9)$ & 0.56 & 0.44 \\
\hline & & & $\operatorname{Inh}^{+}(\mathrm{n}=53)$ & 0.74 & 0.26 \\
\hline & & & $\operatorname{Inh}^{-}(\mathrm{n}=174)$ & 0.62 & 0.38 \\
\hline \multirow[t]{7}{*}{ Africans } & 0.46 & 0.54 & Yoruba Ibadan, Nigeria & 0.41 & 0.59 \\
\hline & & & Luhya Webuye, Kenya & 0.44 & 0.56 \\
\hline & & & Gambian, Western Divisions, Gambia & 0.44 & 0.56 \\
\hline & & & Mende, Sierra Leone & 0.41 & 0.59 \\
\hline & & & Esan, Nigeria & 0.49 & 0.51 \\
\hline & & & Americans of African Ancestry, USA & 0.57 & 0.43 \\
\hline & & & African Caribbeans, Barbados & 0.47 & 0.53 \\
\hline \multirow[t]{5}{*}{ Europeans } & 0.78 & 0.22 & Utah Residents (CEPH) Northern and Western European Ancestry & 0.88 & 0.12 \\
\hline & & & Toscani, Italia & 0.57 & 0.43 \\
\hline & & & Finnish, Finland & 0.84 & 0.16 \\
\hline & & & British, England and Scotland & 0.84 & 0.16 \\
\hline & & & Iberian Population, Spain & 0.79 & 0.21 \\
\hline \multirow[t]{5}{*}{ East Asians } & 0.63 & 0.37 & Han Chinese, Beijing, China & 0.56 & 0.44 \\
\hline & & & Japanese, Tokyo, Japan & 0.78 & 0.22 \\
\hline & & & Southern Han Chinese & 0.56 & 0.44 \\
\hline & & & Chinese Dai, Xishuangbanna, China & 0.64 & 0.36 \\
\hline & & & Kinh, Ho Chi Minh City, Vietnam & 0.60 & 0.40 \\
\hline \multirow[t]{5}{*}{ South Asians } & 0.71 & 0.28 & Gujarati Indian, Houston, Texas & 0.74 & 0.26 \\
\hline & & & Punjabi from Lahore, Pakistan & 0.76 & 0.24 \\
\hline & & & Bengali, Bangladesh & 0.69 & 0.31 \\
\hline & & & Sri Lankan Tamil, UK & 0.67 & 0.33 \\
\hline & & & Indian Telugu, UK & 0.72 & 0.28 \\
\hline \multirow[t]{4}{*}{ Mixed Americans } & 0.74 & 0.26 & Mexican Ancestry, Los Angeles, USA & 0.77 & 0.23 \\
\hline & & & Puerto Ricans, Puerto Rico & 0.68 & 0.32 \\
\hline & & & Colombians, Medellin, Colombia & 0.70 & 0.30 \\
\hline & & & Peruvians, Lima, Peru & 0.82 & 0.18 \\
\hline
\end{tabular}

n: number; Inh': patients with inhibitor; Inh- : patients without inhibitor; HA: hemophilia A; A.; CEPH: Centre d'Etude du Polymorphism Humain, Paris, France.

autochthonous Native American population, leading to a diversity pattern with differential admixture signatures throughout the country. ${ }^{15}$ The frequencies of the rs3754689 in the three cohorts of the EPIGEN illustrate this, with decreased frequency in the cohort of Salvador (Bahia state), where individuals have a strong African ancestry (Table 2).

The lack of association in our study demonstrates important issues to be addressed in the genetic features implicated in inhibitor development in hemophilia A. Firstly, genetic markers are not necessarily involved in the pathogenesis but linked to a genomic and population structure. Secondly, more admixture populations should be included in the studies to avoid apocryphal genomic markers. Although hemophilia A is a monogenic disease, the phenotype of inhibitor development has multidimensional features. Underestimating the genetic diversity of the patients with hemophilia A might have implications in a subset of biological markers not suited for admixed patients or populations with a diverse demographic history.

In conclusion, in our population of severe/moderatelysevere patients with hemophilia A, the SNP rs3754689 was not shown to be protective of inhibitor development. 
Luciana W. Zuccherato, ${ }^{1}$ Silvana M. Elói-Santos, ${ }^{1}$ Letícia L. Jardim, ${ }^{2}$ Ricardo M. Camelo, ${ }^{2}$ Daniel G. Chaves, ${ }^{3}$ Renan P. Souza, ${ }^{4}$ Edward J. Hollox ${ }^{5}$ and Suely M. Rezende ${ }^{2}$

${ }^{1}$ Complementary Propedeutic Department, Faculty of Medicine, Universidade Federal de Minas Gerais, Belo Horizonte, Minas Gerais, Brazil; ${ }^{2}$ Department of Internal Medicine, Faculty of Medicine, Universidade Federal de Minas Gerais, Belo Horizonte, Minas Gerais, Brazil; ${ }^{3}$ Fundação Hemominas, Belo Horizonte, Minas Gerais, Brazil; ${ }^{4}$ Department of General Biology, Universidade Federal de Minas Gerais, Belo Horizonte, Minas Gerais, Brazil and 'Department of Genetics and Genome Biology, University of Leicester, Leicester, UK

Funding: Fundo Nacional de Saúde (Ministry of Health Grant number 25000.155761/2015-13), CAPES (Grant number 88881.068041/2014-01), CNPq (Grant number 456080/20147). $L W Z$ and $L L J$ received fellows hip from $C A P E S, D G C$ received a BIPDT fellowship from FAPEMIG.

Correspondence: SUELY MEIRELES REZENDE.

suely.rezende@uol.com.br/srezende@medicina.ufmg.br doi:10.3324/haematol.2019.220608

Information on authorship, contributions, and financial \& other disclosures was provided by the authors and is available with the online version of this article at www. haematologica.org.

\section{References}

1. Garagiola I, Palla R, Peyvandi F. Risk factors for inhibitor development in severe hemophilia a. Thromb Res. 2018;168:20-27.

2. D'Angiolella LS, Cortesi PA, Rocino A, et al. The socioeconomic burden of patients affected by hemophilia with inhibitors. Eur J Haematol. 2018;101(4):435-456.

3. Report on the Annual Global Survey 2017. World Federation of Hemophilia. 2018. https://www.wfh.org/en/data-collection. Last accessed: 10 September 2019

4. Rezende SM, Rodrigues SH, Brito KN, et al. Evaluation of a web- based registry of inherited bleeding disorders: a descriptive study of the Brazilian experience with HEMOVIDAweb Coagulopatias. Orphanet J Rare Dis. 2017;12(1):27.

5. Astermark J. FVIII inhibitors: pathogenesis and avoidance. Blood. 2015;125(13):2045-2051

6. Gorski MM, Blighe K, Lotta LA, et al. Whole-exome sequencing to identify genetic risk variants underlying inhibitor development in severe hemophilia A patients. Blood. 2016;127(23):2924-2933.

7. Segurel L, Bon C. On the Evolution of Lactase Persistence in Humans. Annu Rev Genomics Hum Genet. 2017;18:297-319.

8. Jardim LL, Chaves DG, Silveira-Cassette ACO, et al. Immune status of patients with haemophilia A before exposure to factor VIII: first results from the HEMFIL study. $\mathrm{Br} \mathrm{J}$ Haematol. 2017;178(6):971-978

9. Jardim LL, van der Bom J, Brommonschenkel CC, Gouw SC, Rezende SM, on the behalf of the HSG. Inhibitor incidence in haemophilia A under exclusive use of a third-generation recombinant factor VIII concentrate: results of the HEMFIL Cohort Study. Br J Haematol. 2018 Dec 17. [Epub ahead of print]

10. Camelo R, Magalhaes L, Jardim L, et al. Immune Tolerance Induction in Patients with Hemophilia $\mathrm{A}$ and Inhibitors: Preliminary Results of the Brazilian Immune Tolerance (BrazIT) Study. Res Pract Thromb Haemost. 2018;2(Suppl. 1):97-98.

11. Blanchette VS, Key NS, Ljung LR, et al. Definitions in hemophilia: communication from the SSC of the ISTH. J Thromb Haemost. 2014;12(11):1935-1939.

12. Kehdy FS, Gouveia MH, Machado M, et al. Origin and dynamics of admixture in Brazilians and its effect on the pattern of deleterious mutations. Proc Natl Acad Sci U S A. 2015;112(28):86968701.

13. 1000 Genomes Project Consortium. Auton A, Brooks LD, Durbin RM, et al. A global reference for human genetic variation. Nature. 2015;526(7571):68-74.

14. Friedrich DC, Santos SE, Ribeiro-dos-Santos AK, Hutz MH. Several different lactase persistence associated alleles and high diversity of the lactase gene in the admixed Brazilian population. PLoS One. 2012;7(9):e46520.

15. Parra FC, Amado RC, Lambertucci JR, Rocha J, Antunes CM, Pena SD. Color and genomic ancestry in Brazilians. Proc Natl Acad Sci U S A. 2003;100(1):177-182. 